\title{
Implementing Constructivist Pedagogical Model in Dynamic Distance Learning Framework
}

\author{
Shakeel A. Khoja ${ }^{1}$, Faisal Sana ${ }^{2}$, Abid Karim ${ }^{2}$, Arif Ali Rehman ${ }^{2}$ \\ ${ }^{1}$ Learning Societies Lab, University of Southampton, Southampton, U.K, \\ sk07v@ecs.soton.ac.uk \\ ${ }^{2}$ Department of Computer Science and Engineering, Bahria University, Pakistan, \\ fasialsana@hotmail.com, abid@bimcs.edu.pk, rehmanaf@bimcs.edu.pk
}

\begin{abstract}
The objective of this paper is to develop an educational framework, using data mining technologies, with the help of dynamic web technologies that will be used by teachers to organize the course contents on the web according to existing infrastructure, experience, needs, and later on reorganizing it if necessary, depending upon the performance of students. The approach to organize the lecture contents is based on the adaptive learning theory, incorporating Problem Based Learning (PBL) strategy. Presently, the course syllabus and handouts on the web sites provided to the student are static in nature. Once distributed, these documents cannot be changed or modified, and also lack depth. When course materials are placed on the web, students can select a topic in the course outline and look at the description of a topic, and required reading assignments. Instructors can easily change schedules in these on-line documents and inform the students via e-mail. Students can also submit assignments, projects and take-home exams electronically. A course home page is comprised of syllabus, assignments, projects and exams, readings and references, class presentation charts and student handouts. Students in a course are mostly assessed on the basis of the questions like why, how what, etc. In this way a student can be graded and ranked, which in turn provide the feedback to student for future improvements and challenges. Most of the web sites are implemented on the theory of constructivism. Constructivists propose that the construction for new knowledge starts from one's observations of events through past experiences. Hence, learning is the integration of new knowledge and behaviors into a framework and subsequently recalling relevant events in the appropriate situation. This theory is also applied in our educational framework.
\end{abstract}

Keywords: E-learning Systems, Problem Based Learning, Pedagogies, Constructivist theory

\section{Introduction}

Education is undergoing a major paradigm shift towards learning rather than teaching. Learning is no longer considered as a process transferring and distributing knowledge to the students. It is now viewed as a transformational process whereby students 
acquire facts, principles, and theories as conceptual tools for reasoning and problem solving in meaningful contexts. From the technological perspective, internet is playing an important role for such student based learning. The objective of this paper is to develop an e-learning framework that will be used by teachers and knowledge providers to organize the course contents for distance learning through existing infrastructure, experience, needs, and later on reorganizing it if necessary, depending upon the performance of students, by adapting evaluation techniques. The approach to organize the lecture contents is based on the adaptive learning theory. Finally a good amount of emphasis is given on evaluation procedures that the tutor can adopt to evaluate the students, in order to provide these students course contents, based on their learning curve.

Learning mechanisms and learning styles are changing at a rapid pace. Learners get more and rapid learning through new technologies such as electronic media. The trend of education has largely shifted towards the web based learning environment with the ever-increasing popularity of the Internet. More and more web based learning sites, VLEs (Virtual Learning Environments) and LMSs (Learning Management Systems) are becoming common, providing various mediums of interaction amongst tutors and learners. The most commonly used mediums are passive posting of study material, Internet chat and email. A number of software and learning systems have been developed using these technologies, such as Blackboard, WebCT, etc; however the usage of Web2.0 technologies (RSS, social bookmarking, blogs, etc) is still in its early stage [1]. The major problem among the above mentioned mediums is the lack of face-to-face communication between the tutor and the learner.

The delivery of information and learning through a web based instructional systems could be done by using text, graphics, sounds, video, etc. To provide true replica of real world learning, these systems should also provide reference sections of the topics that are being offered on that site, which could be in the form of hypermedia. But still it lacks the learning through behaviors i.e. the learning with the help of gestures and face-to-face question and answer sessions. To overcome this, web based systems use 3-D or video chat sessions (Microsoft Net Meeting, CUseeMe, etc) and email group discussions. Sites constructed like this are said to be implemented on the theory of constructivism [2]. Once the material distribution issue is resolved the issue of assessment becomes active. In real classroom environment a teacher takes quizzes, hands over course works and assignments. Again this could be done using chat and email capabilities of the system. However to keep track of the efforts put in by a student to achieve the learning and ability outcomes of the subject is not yet standardized. Furthermore, most sites are static in nature as for as the organization of the course contents are concerned.

In this paper we will try to address the issues of adaptive learning through student feedback. In the beginning the theory of constructivism is explained then a discussion on learning through constructivism, teaching, teaching / learning on the Web and assessment is provided and finally we propose our solution to the assessment and reorganization of the course contents, if deemed necessary by the tutor, after assessing student's performance. 


\section{Constructivism}

Constructivist theory is highly promising for web-based learning, from which many new strategies are emerging. Constructivists propose that the construction for new knowledge starts from one's observations of events through past experiences one already has. Learning something new involves changing the meaning of one's previous experiences [2]. It can further be debated that under certain conditions, absolutely new concepts might have been developed instead of altering the old ones.

\subsection{Learning: Individual and Social process}

Students decide what they need to learn by setting personal learning goals. Students construct for themselves meaningful knowledge as a result of their own activities and interaction with others [3]. Learning strategies include library research, problem and case-based learning, solving assignments and projects, group work, discussions, and fieldwork. On the contrary, classroom teaching is a stimulus to the student's real learning that mostly takes place outside formal classes. Further unstructured (Constructivism) classes with individualized activities, much discussion and optional attendance will provide more chances of learning then traditional class room methods. Students engage actively with the subject matter and transform new information into a form that makes personal sense to them and connects with prior knowledge. Students are placed immediately into a realistic context with specific coaching provided as needed [4].

The constructivist model is learner-centred. The student must control the pace of learning. The teacher acts as a moderator who facilitates the process of learning. Students learn better when they are allowed to discover things by themselves rather than being told what to learn. Variations of the constructionist theory include the collaborative theory of learning, and the cognitive information-processing model of learning. Constructionist-based theories are very popular and have triggered a paradigm shift in the education process towards a student-centred learning approach. This means that there should be some contact between the teacher and the student for the achievement of learning and ability outcomes of a subject. A leaner builds his/her knowledge by building up a knowledge base according to a sequence that suits his/her learning process. Hence every learner has a different experience of learning. A learner can acquire knowledge from social interaction (social-constructivism) with others [2]. According to different theories of learning [4], it could be summarized that the ability to learn is the result of some sort of input and then constructing the meaning from it. Learning consists both of constructing meaning and constructing systems of meaning [5]. There could be many factors involved the process of learning of learner e.g. language, environment and the medium of communications.

\subsection{Modern Style of Learning}

Learning is the integration of new knowledge/ behaviors into a framework and subsequently recalling what is relevant in the appropriate situation. To understand 
learning we must consider how new information is received and the stage through which new information is processed as it progresses from immediate sensory experience to long-term storage. It is also important to understand how novices and experts organize, analyze, or encode, and then retrieve necessary information. Teaching consists of organizing, planning, delivering and evaluating the content of the subject area. Figure 1 shows the basic elements and their relation in an adaptive learning environment. Learning is contingent upon perception. It improves concept formation- the essential element of human thought. Learning is benefited by memory and is achieved through thoughtfulness and critical thinking [5].

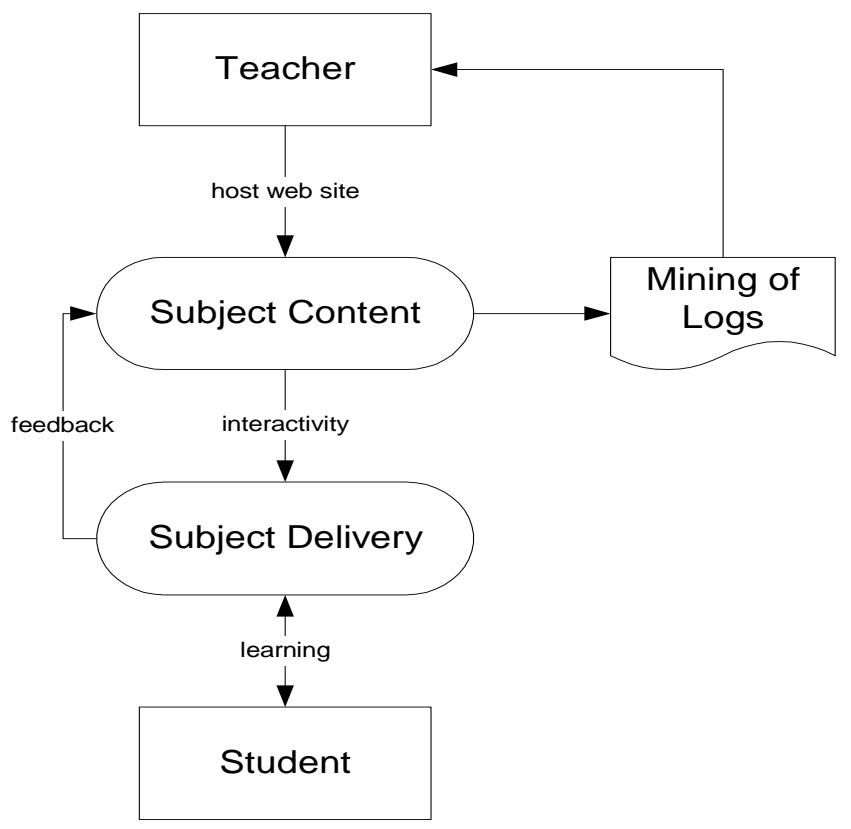

Fig.1. Adaptive Learning methodology

\subsection{Modern Style of Teaching}

Teaching may best be defined as the organization of learning. So the problem of successful teaching is to organize learning for authentic results. Teaching may be thought of as the establishment of a situation in which it is hoped and believed that effective learning will take place. This situation is complicated and made up of many parts, such as the requirement of a learner, facilities (stated place, time of meeting, books, aids, etc.), orderly and understood procedures, rules for grading and finally an organizer who brings these parts to a complete form- in other words a teacher. Teaching is the organization of learning. Thus it follows that a teacher is essentially an organizer. The task of any organizer is to enable a group and the individuals in it to function effectively together for the achievement of a common purpose [6]. 


\subsection{Teaching / Learning on Web}

Presently, the course syllabus and handouts provided to the student are static in nature. Once published, these documents cannot be changed or modified, and also lack depth. The topics to be covered may be listed in the course outline, but including descriptions makes the document lengthy and thus is rarely done. This makes the course devoid of the requisite flexibility. The costs of duplicating handouts, syllabi, and assignments have proven to be a burden. Sometimes logistical factors prevent a student from receiving an assignment in time.

When course materials are placed on the Web, students can select a topic in the course outline and look at the description of a topic, and required reading assignments. Students can select the exam schedule and look at the topics included for that exam. Assignments and projects can be made available on-line on the WWW. Students can access class materials at anytime and from anyplace (via a computer), save or print handouts, assignments, etc.

Instructors can easily change schedules in these on-line documents and inform the students for example via e-mail. Students can also submit assignments, projects and take-home exams electronically. Alternatively, all the handouts and the hypermedia software can be provided to the students on disk and they can browse the course materials off-line at their convenience.

Traditional course materials were rendered unusable when the software package in which they were created became obsolete. For example, a handout prepared using an old business graphics software cannot be used anymore because it is no longer available in the office or classroom. Instructors also face problems when the software package that they use at home is not available in the office.

Web course materials are software and hardware independent. Instructors can reuse handouts and presentation materials that were created with old or incompatible software, by converting them from the original format straight to a format that can be used on the Web, for example GIF files. Browser software can be used across computer platforms.

\subsection{Assessment of students}

The Web-based informal assessment represents a cognitive behavior modification technique designed to help students develop goal setting behavior, planning and selfmonitoring and provides the opportunity for students to master the concepts. For example, students can regulate and monitor their own learning throughout the course in a sequential and constructive fashion as they respond to the questions and receive ongoing feedback [7]. Students in a course are mostly assessed on the basis of the question like why, how what, etc. In this way a student can be graded and ranked, which gives in turn student a feedback for future improvements and challenges. There are various modes in which a student can be assessed, such as written exam and quizzes, viva voce, projects, lab reports, thesis, dissertation, self assessment, peer assessment and many more. 


\section{Proposed Framework for E-learning using adaptive techniques}

The above sections provided details of the different aspect of education. I this section, we are presenting a framework for E-learning which will aid in developing a prototype and online sites incorporating multimedia tools such as audio, video and graphics, along with the above mentioned aspects of education. Figure 2 depicts the basic elements or our model. This is a student centered model and the teacher's job along with providing education, is to tune certain parameters, through student's feedback, to describe what next should be provided to the student.

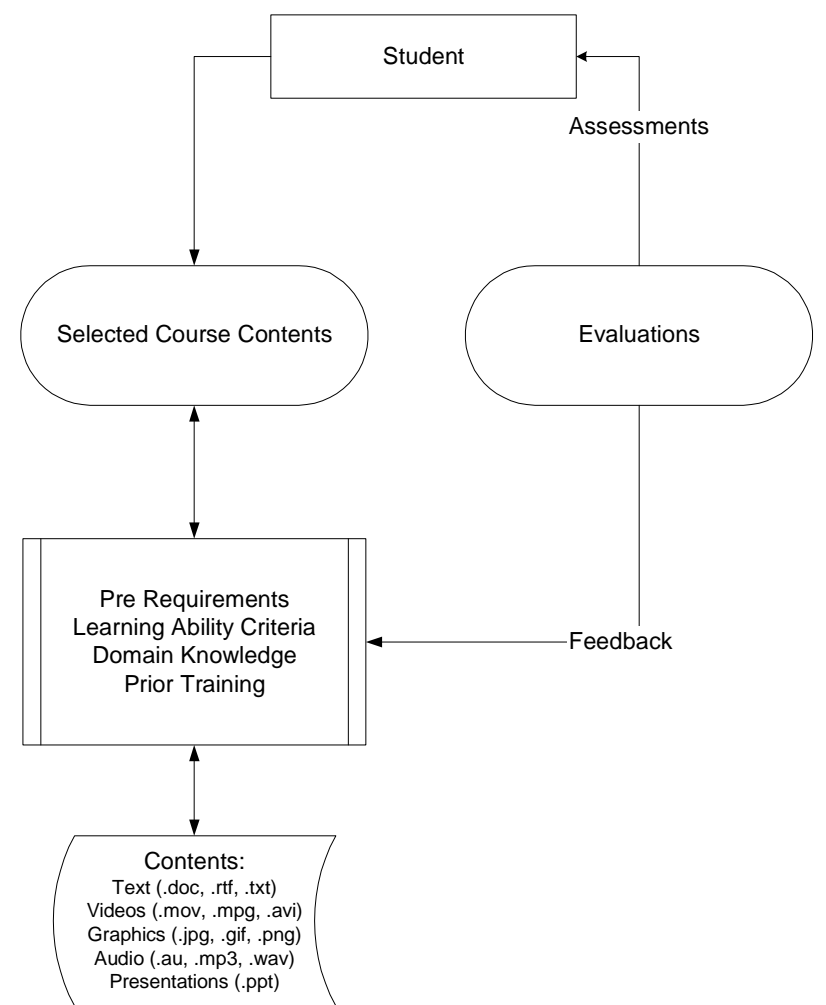

Fig.2. Student Centered Model for Adaptive Learning

PBL utilizes student groups, but each group member is also responsible for independent research. Further, instructor scaffolding is considerably less direct in problem-based learning than in other constructivist models such as anchored instruction. Students are allowed to struggle and induct their own mental model of course concepts with only occasional "life-lines" from the instructor when concept processing falls off-track. Problem-based learning is most similar to case-based instruction, but in its purest form, PBL is more open-ended [8].

Constructivist teaching methods place responsibility on students for managing their own, learning while the teacher guides them and manages their learning environment. Students are given tasks and opportunities, information resources and support, and 
encouraged to construct their own knowledge structure which is guided through feedback and revision. Learning strategies include library research, problem and casebased learning, doing assignments and projects, group work, discussions, and fieldwork. Classroom teaching is a stimulus to the student's real learning that mostly takes place outside formal classes $[9,10]$.

\section{Implementing Framework}

The proposed framework would be developed on the basis of both the constructivism theory and PBL. For the case study, Object Oriented Programming courses are inspected. The course contents are developed on a wider assessment difficulty index of easy, moderate and difficult (to be decided by the tutor). For example, topics in which the syntax and the basics of a language are discussed could be placed in easy difficulty index category. Topics which discuss the use of already made utilities and supporting files could be placed in the moderate difficulty index. Finally, Difficult index could encompass topics which are dependent on some other subjects e.g. networks, videos, etc.

The difficulty index would be different for each course according to targeted audience and would be decided by tutor by allocating less points for topics that lie in the easy level, average points for moderate level and maximum points for topics difficult index level (a linear mechanism). Each topic taught would increase learner's knowledge points by a predefined increment. If a learner's knowledge points match or come closer the tutor defined outcome points of the course, a student would be considered to have good problem solving skills. If no one or only few come closer to outcome points, the tutor can reorganize the course contents in the difficulty index to achieve the expected outcomes.

\subsection{Web Based implementation}

The site is developed using the server side technology (.net). Tutors (authors of course) and learners are required to register themselves in a course. A profile is stored for every user. Along with, data fields are provided for storing pre-requirements, learning abilities, domain knowledge, prior training and feedback received. Options for Live Video sessions and streaming the stored video clips are also provided. For arranging Live Video sessions, we use standard video conferencing equipment with the capacity to connect up to 200 users. The equipment uses a built-in web server to stream videos. At the client site, Media Player is used to view live videos. For interactive chats, we have developed customized software, where the registered students can login in particular class rooms. In the profile, student thumbnail pictures of the students are also provided. In order to create interactivity with the videos, it is envisaged that flash video format and its player will be used in the system. 


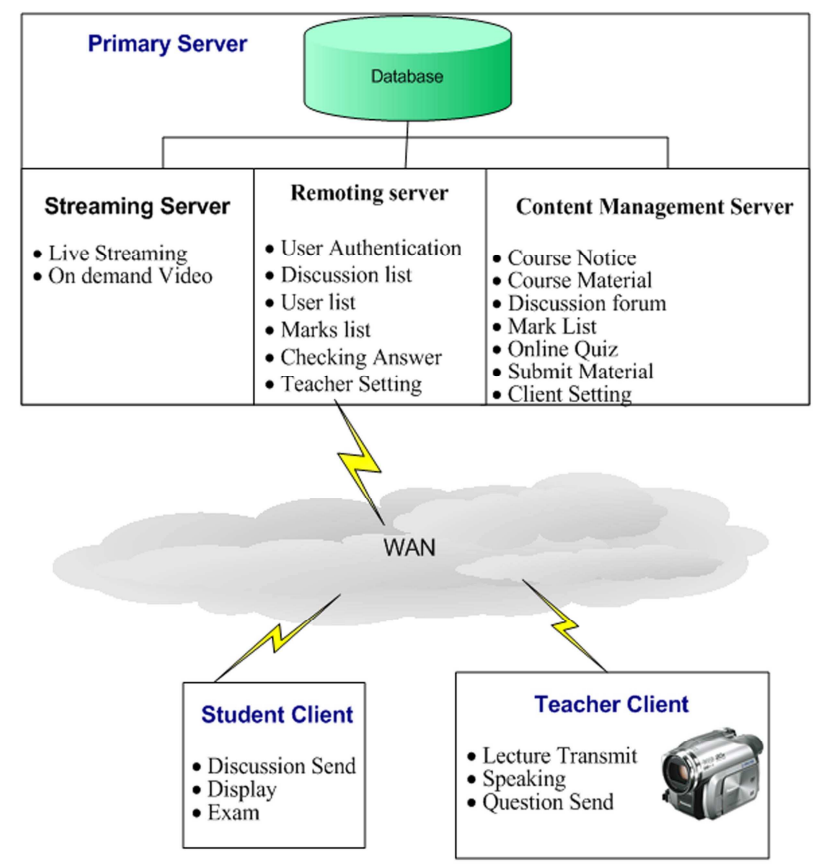

Fig.3. Main System Architecture

In this system, interaction between lecturer and students is done through questions, in form of text messages question. Students ask questions regarding current lecture is centrally maintained in a list and displayed on each students' and teacher's client screen. Teacher or his/her assistant can pick a question from the list and give answer either through text reply or can comment during his/her lecture. To check the involvement of student in a lecture, teacher or his/her assistant sends few questions for students at random time during the lecture. Students will be required to answer these periodically prompting multiple choice questions during the lecture hour. System will verify these answers and makes result on the base of their responses. The main architecture has three major parts: primary server, teacher client and student client, as shown in figure 3. 


\subsection{Primary Server}

Primary server is a combination of remote server, streaming server, content management server and database server. Remote server handles communication between Primary and other parts of main system by using .Net Remoting[12]. Streaming sever is used for live transmitting and on demand video. Content management server deals with asynchronous learning. Following are the main features of primary server.

Discussion list: This list contains the entire questions that have been asked by students during lecture hours. Student client has ability to add new questions in the list and also teacher can add answers in special case. This list is display on both teacher and students client screen.

Live Streaming: This uses media server [13] for live lecture video transmission. This maintains a transmission point for each teacher.

Online Quiz list: Teacher client will be able to invoke this method by using their teacher id and course id. It returns all online quiz marking schemes and their respective questions to teacher client.

Auto Checking Answer Module: Receive each student multiple choice question response and then made the result on the basis of their answer. This method is invoked by student client.

Customized Marks List: This allows each teacher to customize design marks list accordance with their subject requirement. Each marks column has further online quiz option, allowing teacher to add a question list for online quiz.

Auto Online Quiz: This function is used for taking remote student examination. This part takes input from customized marks list function that provides quiz question list. After processing each student response, this module update marks list.

Course Notice: This contains all notices related to a course which also include university announcements and other student related tasks.

Course Material: This provides a way to teacher to post their course materials. This maintains separate material repository for each teacher course. Only students enrolled in the course may view them.

Discussion forum: This provides a good means of public communication, allowing instructors and students to post and reply to messages. Discussion forums can be used for assignments, FAQ's, collaborative work, peer critique of work, etc.

Submit Material: This function is use to handle all submission record of remote student and also handles the submission update issues.

\subsection{Instructor Module}

Instructor Module part is made for teacher facilitation. This consists of following main features.

Lecture Delivery Module: This uses encoder [14] that transmits the live lecture video to primary server. Then primary server part, live streaming further transmits it to student clients.

Speaking Agent: We have use agent [15] that will speak up question of discussion list in a user control manner.

Quiz Module: It will contain the results of primary server's mark list function. It allows the teacher to view each marking scheme questions and then allow sending these questions to student client for checking involvement. 


\subsection{Student Module}

This part is made for students. Following are the main features of student client. Discussion Module: This is used for adding new question to discussion list of primary server.

Display: Media player [11] is used to view lectures.

Checking Module: This is used to examine the students performs with multiple choice question, sent by teacher, which will appear in this area for short interval during the lecture, and student's response will automatically confirm and store in a database table by using primary server checking answer function.

Instructor is responsible for organizing subject materials according to the introduction of the topic and the sub-topics in a particular lecture are cross-referenced using hyperlinks on to other web pages. Those sub-topics fall in the categories of explanations, examples, questions and references. It is the responsibility of the tutor to develop and maintain the formula by using the above mentioned entities, to decide whether a student is allowed to proceed further. The development and study of this formula is beyond the scope of this paper. Currently in our framework, we have adopted linear incremental method for modifying difficulty index.

Each course on the site is created on the basis of course title. Followed by a topic, and sub-topics in a particular index of difficulty, learners can navigate a topic using links on a page for its sub-topic. Each link clicked increases a student's points for directed unsupervised activity. If a page is clicked from its sub-topic it will not constitute to the points of a student. Once the learner has finished reading through the topic, he/she can check his/her skills by appearing in a quiz. The scored marks in the quiz are added to already scored points through navigation of pages. This way, students' performance is checked by comparing their old scores with the current ones.

At the end of the course a tutor can calculate the average of students' performance, which in turn will be matched with his expected points for each difficulty index. If there is any difference found then the tutor can change the criteria of difficulty index.

\section{Conclusion and Future Aspects}

The next step in this direction is to analyze the learning pattern of a student over a period of time by mining his/her performance throughout. This will result in an improvement in the customized delivery of course material to students. Currently many researchers are putting their efforts towards adaptive learning environment. So the results from our E-learning framework will help to dynamically organize notes according to student's learning abilities. This research is not limited to text only but will also incorporate extensive research in voice and video for semantically organized content-based retrieval. This will aid in conducting online lectures to simulate a realworld classroom environment.

The paper has considered theoretical and research issues associated with design and use of an E-learning framework. Overall this study has found evidence that an E- 
learning framework incorporating adaptive learning techniques, its models and architectures for WWW, provide more help to students for interactive learning as compared to traditional systems.

\section{References}

1. Ebner, M.: E-learning2.0 = e-Learning $1.0+$ Web 2.0?, Second International Conference on Availability, Reliability and Security, 2007(ARES 2007), pp. 1235 -- 1239, (2007)

2. Zhi-Feng Liu, E., Sunny S. J., Lin, Chiu, C., and Yuan S.: Web Based Peer Review: The learner as both Adapter and Reviewer, IEEE Transactions of Education, Vol 44, No. 3, Page(s). 246-251 (2001)

3. Montgomery S.M.:, Addressing Diverse Learning Styles Through the Use of Multimedia, ASEE/IEEE Frontiers in Education Conference, (1995)

4. Bill Pelz, C.A.S:, My three principles of effective online pedagogy, Journal of Asynchronous Learning Networks (JALN) Volume 8, Issue 3 (2004)

5. Fardouly N.: "Learner-Centered Teaching Strategies", in Principles of Instructional Design and Adult Learning Series, The University of New South Wales, Australia, September 1998. http://www.fbe.unsw.edu.au/learning/instructionaldesign/strategies.htm (1998)

6. Hein, G.E.: Constructivist Learning Theory, International Committee of Museum Educators Conference (CECA), Jerusalem Israel, pp.15--22 (1991)

7. Buriak,P., McNurlen, B., and Harper,J.: Systems Model for Learning, in ASEE/IEEE Frontiers in Education 95 Conference, Atlanta, USA, (1995)

8. Ashcroft, K. and Foreman-Peck, L.: Managing Teaching and Learning in Further and Higher Education. Routledge, London: The Falmer Press, (1994)

9. Hazari,S., and Schno,D.: Leveraging Student Feedback to Improve Teaching in Web-based Courses, Feature Article, THE Journal, (1999)

10.Sana, F., Khoja, S.A., A low cost interactive distance learning solution, in $66^{\text {th }}$ Annual IEEE/ACIS International conference on Computer and Information Science (ICIS2007), Melbourne, Australia,(2007)

11.McLean, S., Naftel, J., and Williams K.: "Microsoft .NET Remoting", Microsoft Press, Washington, (2002)

12.Microsoft Technical Manual, Window Media Server, http://www.microsoft.com/windowsserver2003/technologies/winmedia/default.mspx

13. Microsoft Technical Manual, Window Media Encoder, http://www.microsoft.com/windows/windowsmedia/forpros/encoder/default.mspx

14.Deitel, H.M., Deitel, P.J., Deitel, T.R.: Visual Basic.Net: How to Program, Prentice Hall, New Jersey, (2002).

15.Microsoft Technical Manual, Window Media Player, http://www.mic rosoft.com/windows/windowsmedia/player/9series/default.aspx 